\title{
Precious metal-free molecular machines for solar thermal energy storage
}

\author{
Meglena I. Kandinska ${ }^{1}$, Snejana M. Kitova ${ }^{2}$, Vladimira S. Videva ${ }^{1,2}$, \\ Stanimir S. Stoyanov ${ }^{1}$, Stanislava B. Yordanova ${ }^{1}$, Stanislav B. Baluschev ${ }^{3}$, \\ Silvia E. Angelova ${ }^{*}$ and Aleksey A. Vasilev ${ }^{* 1}$
}

\section{Full Research Paper}

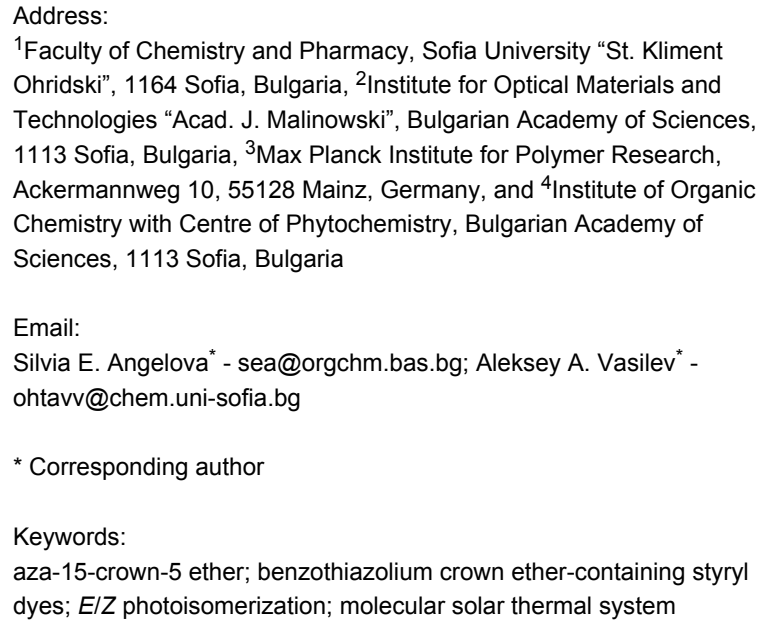

${ }^{1}$ Faculty of Chemistry and Pharmacy, Sofia University "St. Kliment Ohridski", 1164 Sofia, Bulgaria, ${ }^{2}$ Institute for Optical Materials and Technologies "Acad. J. Malinowski", Bulgarian Academy of Sciences, 1113 Sofia, Bulgaria, ${ }^{3}$ Max Planck Institute for Polymer Research, Ackermannweg 10, 55128 Mainz, Germany, and ${ }^{4}$ Institute of Organic Chemistry with Centre of Phytochemistry, Bulgarian Academy of Sciences, 1113 Sofia, Bulgaria

Email:

Silvia E. Angelova* - sea@orgchm.bas.bg; Aleksey A. Vasilev* ohtavv@chem.uni-sofia.bg

* Corresponding author

Keywords:

aza-15-crown-5 ether; benzothiazolium crown ether-containing styryl dyes; $E / Z$ photoisomerization; molecular solar thermal system

Beilstein J. Org. Chem. 2019, 15, 1096-1106. doi:10.3762/bjoc.15.106

Received: 25 February 2019

Accepted: 29 April 2019

Published: 14 May 2019

This article is part of the thematic issue "Novel macrocycles - and old ones doing new tricks".

Guest Editor: W. Jiang

(C) 2019 Kandinska et al.; licensee Beilstein-Institut. License and terms: see end of document.

\begin{abstract}
Four benzothiazolium crown ether-containing styryl dyes were prepared through an optimized synthetic procedure. Two of the dyes (4b and 4d) having substituents in the 5-position of the benzothiazole ring are newly synthesized compounds. They demonstrated a higher degree of trans-cis photoisomerization and a longer life time of the higher energy forms in comparison with the known analogs. The chemical structures of all dyes in the series were characterized by NMR, UV-vis, IR spectroscopy and elemental analysis. The steady-state photophysical properties of the dyes were elucidated. The stability constants of metal complexes were determined and are in good agreement with the literature data for reference dyes. The temporal evolution of trans-to-cis isomerization was observed in a real-time regime. The dyes demonstrated a low intrinsic fluorescence of their $\mathrm{Ba}^{2+}$ complexes and high yield of $E / Z$ photoisomerization with lifetimes of the higher energy form longer than 500 seconds. Density functional theory (DFT) calculations at the B3LYP/6-31+G(d,p) level were performed in order to predict the enthalpies $(H)$ of the cis and trans isomers and the storage energies $(\Delta H)$ for the systems studied.
\end{abstract}

\section{Introduction}

Molecular photoswitches permanently attract considerable interest because they hold potential for application in molecular electronic and photonic devices [1-5]. Photoswitches are a class of switches that can alternate between the thermodynamically stable forms by application of light (or change of the light intensity) as an external stimulus. If the stable forms (isomers) are 
not isoenergetic, they have the ability to capture and store imported (solar) energy [6]. As the stored energy is further released as thermal energy, such materials are called molecular solar thermal systems (MOST) [7]. For a pure MOST system the maximal solar energy conversion efficiency was estimated to be $10.6 \%$ [8]. It was demonstrated experimentally that by merging a MOST-system [9] with a triplet-triplet annihilation photon energy upconversion system (TTA-UC) [10,11] an effective utilization of sub-bandgap photons is possible [12,13] Nevertheless, the identification of a precious metal-free MOST system utilizing the visible part of the sun spectrum remains a considerable challenge.

The stated requirements for such systems can be summarized as follows [7]:

(i) the potential barrier between the higher energy form and the lower energy form of the energy carriers should be as high as possible;

(ii) the higher energy form must be stable for a long time;

(iii) the higher energy form has to be with quite small molar absorptivity in comparison to the lower one;

(iv) the quantum yield of the photoisomerization has to be as high as possible, which requires the design of MOST systems with completely suppressed or minimal fluorescence, intramolecular charge transfer or other processes, quenching the photoisomerization;

(v) the energy storing MOST materials have to utilize light in the visible range of the spectrum;

(vi) it will be a crucial benefit for the MOST technology, if toxic and precious metals are avoided. Focusing on environmentally friendly MOST system is an unavoidable requirement;

(vii) the MOST materials should be of low cost and easily accessible; their synthesis and purification should be straightforward, reliable, fast, inexpensive and ideally environmentally benign.

Therefore, only MOST systems fulfilling all requirements (i)-(vii) simultaneously can be regarded as realistic technological systems for long-term solar energy storage.

However, the design and preparation of molecules matching all the above-mentioned criteria is quite difficult. Thus, the invention of new materials possessing at least parts of these require- ments provides the base for further improvements and brings the scientists nearer to the identification of the "perfect" MOST system. In this connection we identified crown ether-containing styryl dyes $[14,15]$ as promising substances due to their ability to undergo trans-to-cis photoisomerization $(E / Z)$ with very high quantum yields. In addition, their structures predispose to an easy functionalization and low cost synthesis. Another advantage of these dyes is the very low molar absorptivity [16,17] of the higher energy cis isomer, which is a prerequisite for its photostability. The cis isomers of styryl dyes linked to crown ethers have been identified to form complexes with alkalineearth metal cations with higher stability constant than the respective trans isomer forms [14,15,18]. Lednev et al. proposed as an explanation of the difference in the determined stability constants values for the complexes with cis/trans isomers the formation of an additional intramolecular coordination bond between the "crowned" cation and the alkylsulfonate anchoring group which is only possible for the cis form [19]. The further studies by the same group of authors indicated that benzothiazolium styryl monoazacrown ether dyes have several main advantages. First of all, the azacrown nitrogen atom is linked directly to the dye and it is part of the chromophore system, responsible for the "push-pull" effect and the photophysical properties of the dye. This provides control over the "push-pull" effect in the chromophore by switching on and off states (i.e., metal-in/metal-out from the crown ligand) [20]. Further, it was found that the azacrown benzothiazolium styryl dyes $4 \mathbf{a}$ and $\mathbf{4 c}$ exhibit ion-sensitivity in the thermal cis-trans photoisomerization [18,21], a feature, which may be used in the development of thermoreversible photoionic molecular devices [19]. Crown ether-containing styryl dyes are used as sensors for dications such as $\mathrm{Ba}^{2+}, \mathrm{Ca}^{2+}$ and $\mathrm{Mg}^{2+}$, or as materials for optical data storage [19]. Thus, to the best of our knowledge this kind of dyes has not been specified as potential MOST material yet.

The aim of the present study is to reveal the potential of the aza15-crown-5-containing styryl dyes as efficient material for the TTA-UC accelerated MOST process.

\section{Results and Discussion Synthesis}

The synthetic pathway starts with the quaternization of 2-methylbenzothiazoles $\mathbf{1 a}$ and $\mathbf{1 b}$ with 1,3-propanesultone (1c) or 1,4-butansultone (1b) in a sealed tube at $145{ }^{\circ} \mathrm{C}$ without any solvent, as it was described in the literature [17] (Scheme 1).

A four-step synthetic pathway was used for the synthesis of 4-(aza-15-crown-5)benzocarbaldehyde 3 (Scheme 2) following the procedure described in [22]. 
<smiles></smiles>

2a: $\mathrm{X}=\mathrm{H}, n=1(81 \%)$
2b: $\mathrm{X}=\mathrm{CH}_{3}, n=1(93 \%)$

2c: $\mathrm{X}=\mathrm{H}, n=2(91 \%)$

2d: $\mathrm{X}=\mathrm{CH}_{3}, n=2(90 \%)$

Scheme 1: Quaternization of 2-methylbenzothiazoles with alkane sultones.

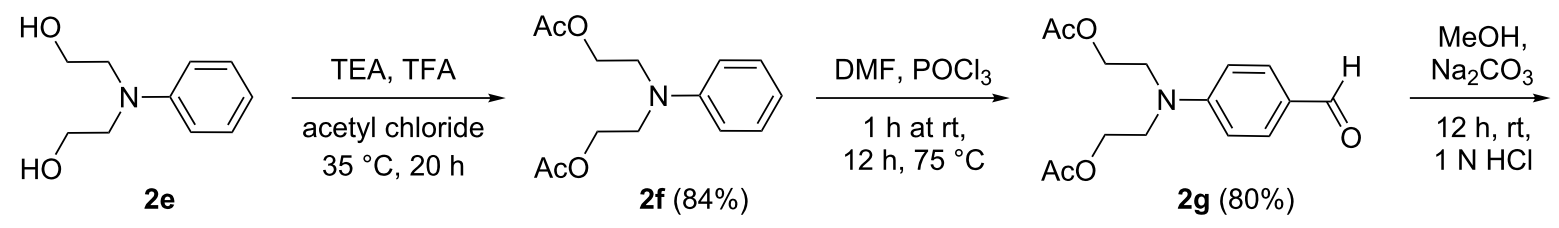<smiles>O=Cc1ccc(N(CCO)CCO)cc1</smiles>

2h $(58 \%)$

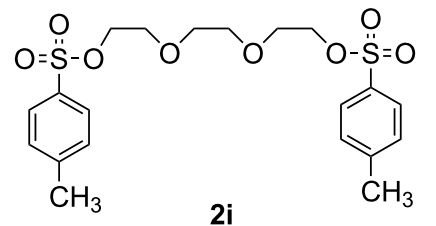

$\mathrm{NaH}, \mathrm{THF}$
$2 \mathrm{~d}, 70^{\circ} \mathrm{C}$

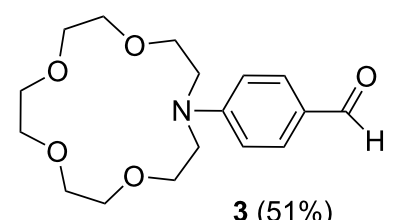

$3(51 \%)$

Scheme 2: Synthesis of 4-(aza-15-crown-5)benzocarbaldehyde (3) [22].

A series of the target dyes $\mathbf{4 a - d}$ was prepared using a modified literature procedure (Scheme 3) [22]. The modification consists in the addition of a $10 \%$ molar excess of 4 -(aza-15-crown5)benzocarbaldehyde (3, Scheme 3$)$ and usage of ethyl acetate as an additional solvent for product precipitation. Because of its better solubility in ethyl acetate the unreacted excess of crown ether 3 was easily removed. In general the zwitterionic salts 2a-d reacted to complete depletion in ethanol and in the presence of piperidine as catalyst with the crown ether benzaldehyde 3 (TLC monitoring, ethyl acetate/ethanol 4.5:0.5). After the addition of ethyl acetate the precipitated target products 4a-d were isolated by filtration.
It must be mentioned explicitly, that the modification of the procedure helped us to avoid cost-intensive and timeconsuming purification procedures which makes the synthesis suitable for large material quantities. In this way only one further precipitation from ethanol/ethyl acetate 1:3 was needed to obtain analytically pure target dyes $\mathbf{4 a - d}$.

The dyes $\mathbf{4 a}$ and $\mathbf{4} \mathbf{c}$ were previously described $[18,21]$ and were used as reference compounds. To the best of our knowledge dyes $\mathbf{4 b}$ and $\mathbf{4 d}$ are new compounds. The chemical structures of all dyes from the series were proved by NMR spectroscopy, elemental analysis, IR and UV-vis spectroscopy.

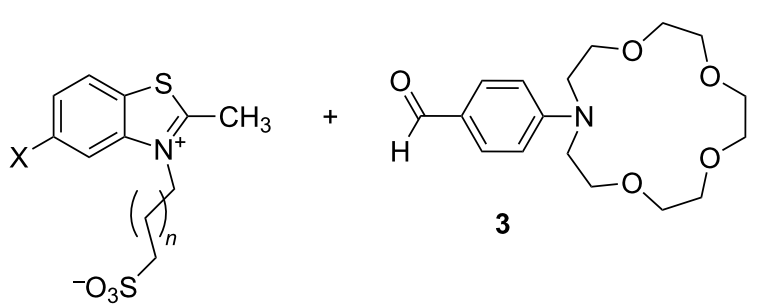

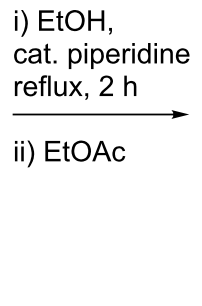

2a: $\mathrm{X}=\mathrm{H}, n=1$

2b: $\mathrm{X}=\mathrm{CH}_{3}, n=1$

2c: $\mathrm{X}=\mathrm{H}, n=2$

2d: $\mathrm{X}=\mathrm{CH}_{3}, n=2$

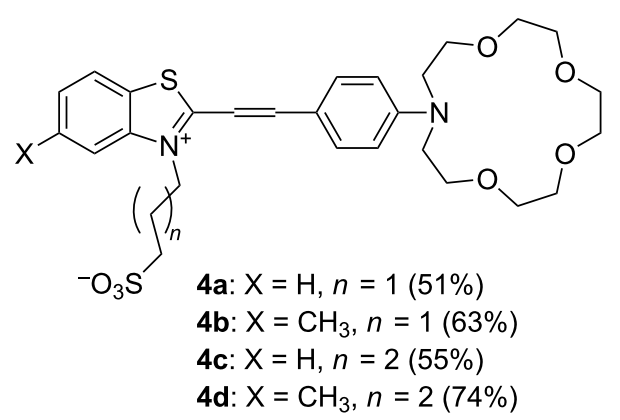

Scheme 3: Synthesis of dyes $4 a-d$. 


\section{Photophysical properties}

\section{Steady-state absorption and emission spectroscopy}

Next we elucidated the photophysical properties of the chosen compounds and determined their suitability to be used as MOST systems. First, we defined their photophysical behavior in neat acetonitrile $(\mathrm{ACN})$ solution and in the presence of barium cations. Figure 1 shows the absorption spectra of dyes 4a-d measured at different concentrations $\left(c_{\mathrm{M}}\right)$ of $\mathrm{Ba}\left(\mathrm{ClO}_{4}\right)_{2}$. All dye solutions have similar absorption profiles with a broad long wavelength band in the vis region $(\Delta \lambda=400-600 \mathrm{~nm})$ with long wavelength maxima at $\lambda_{\max }=520 \mathrm{~nm}$ indicating that their spectral properties are determined principally by the core chromophore structure. The addition of $\mathrm{Ba}^{2+}$ ions to the ACN solution of all dyes induced a decrease in the absorption maximum intensity (at about $520 \mathrm{~nm}$ ) and to a substantial hypsochromic shift of the maximum absorption with peak at around $\lambda_{\max }=440 \mathrm{~nm}$. The changes in the absorption spectra of the dyes upon the addition of $\mathrm{Ba}\left(\mathrm{ClO}_{4}\right)_{2}$ in $\mathrm{ACN}$ solution are characteristic for an ion complexation by the azacrown ether group of the chromoionophore and the spectra in Figure 1 were assigned to the formation of the trans-dye- $\mathrm{Ba}^{2+}$ complex [19]. For all dye solutions, a distinct isosbestic point upon titration was observed, indicating only one kind of complex formation even at the highest $\mathrm{Ba}^{2+}$ concentration.

To determine the optimal $\mathrm{Ba}^{2+}$ concentration for our measurements it was necessary to define the stability constants for each dye- $\mathrm{Ba}^{2+}$ complex. The dependencies of the absorption $A$ (Equation 1) of the dyes $\mathbf{4 a - d}$ at a fixed wavelength $\lambda=520 \mathrm{~nm}$ on the $\mathrm{Ba}^{2+}$ concentration in ACN is shown in Figure 1d. The curves were approximated by Equation 1, which is true for the simplest form of complexation [18]:

$$
A=\left[A_{0}+A_{\infty} K c_{\mathrm{M}}\right] /\left[1+K c_{\mathrm{M}}\right]
$$

$$
L+M \rightarrow L M
$$
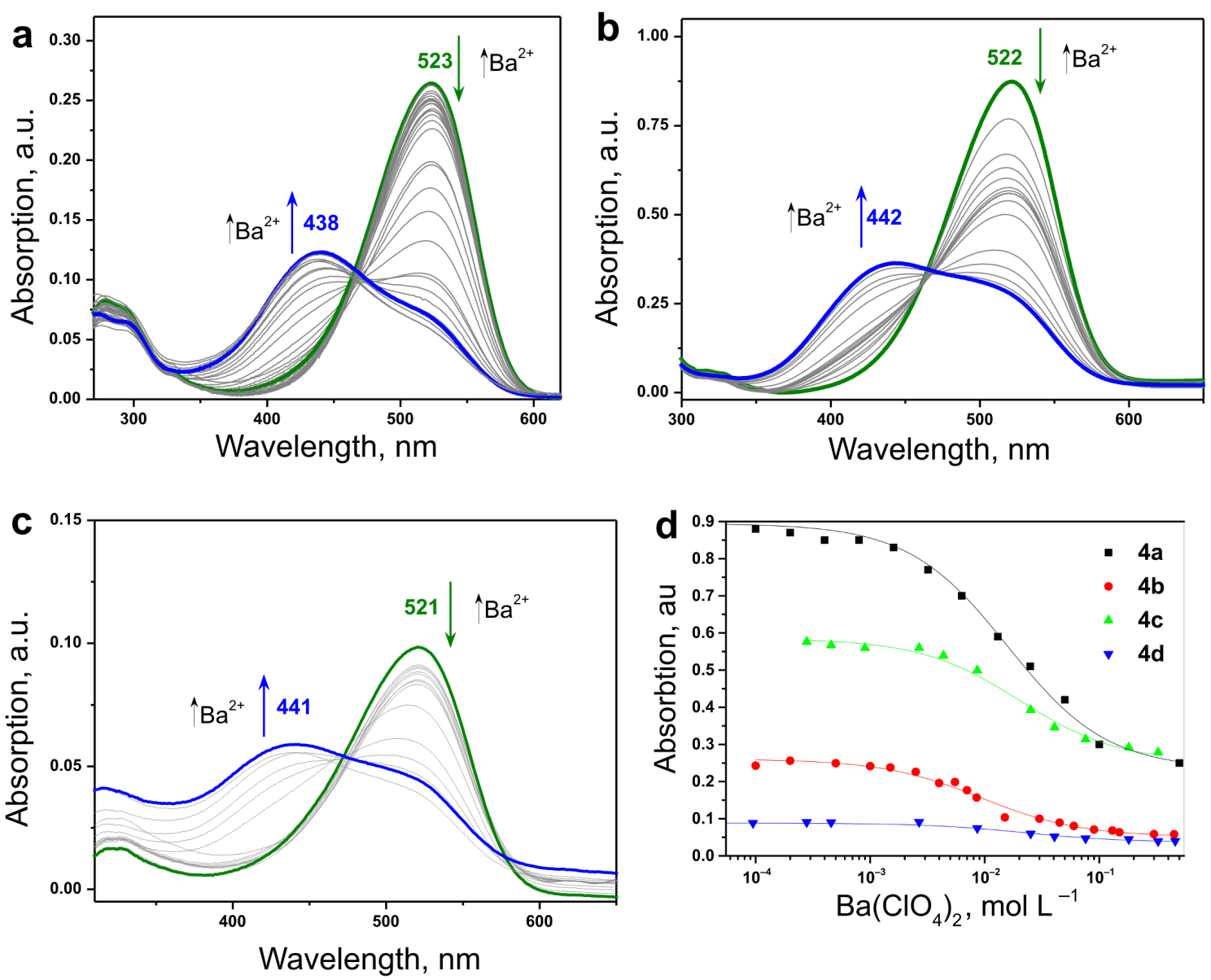

Figure 1: a-c) Dependence of the absorption spectra of the dyes $\mathbf{4 b}, \mathbf{4 c}$ and $\mathbf{4 d}$, respectively $\left(c_{\mathrm{L}}=1.0 \times 10^{-5} \mathrm{M}\right.$ in $\left.\mathrm{ACN}\right)$ on the concentration of $\mathrm{Ba}\left(\mathrm{ClO}_{4}\right)_{2}$, ranging from $1 \times 10^{-4} \mathrm{M}$ up to $5 \times 10^{-1} \mathrm{M}$. d) Absorption of dyes $4 \mathrm{a}-\mathbf{d}$ at $\lambda=520 \mathrm{~nm}$ as a function of $\left.\mathrm{Ba}(\mathrm{ClO})_{2}\right)_{2}$ concentration. Experimental conditions: rt, sample thickness $d=10 \mathrm{~mm}$. 
where $A_{0}$ and $A_{\infty}$ are the absorptions of the chromoionophore at zero and infinite concentration of the metal ion, respectively; $A$ is the absorption at the concentration $c_{\mathrm{M}}$ of the metal ion; $K$ is the stability constant of complex formation, and $L$ and $L M$ are the ligand and the metal ion complex, respectively. $A_{\infty}$ and $K$ were found by approximation of Equation 1.

The stability constant for the complex formation was estimated to be $K=100 \pm 15 \mathrm{M}^{-1}, 49.4 \pm 7.6 \mathrm{M}^{-1}$ and $44.7 \pm 10 \mathrm{M}^{-1}$ for dyes $\mathbf{4 b}, \mathbf{4 c}$ and $\mathbf{4 d}$, respectively. For dye $\mathbf{4 a}$ the stability constant was found to be $K=70 \pm 15 \mathrm{M}^{-1}$ which is in good correlation with the published data [22]. These results prompted us to identify the optimal $\mathrm{Ba}^{2+}$ concentration, necessary for a maximum degree of dye- $\mathrm{Ba}^{2+}$ inclusion complex formation. Obviously for a better complexation it is necessary to work with high $\mathrm{Ba}^{2+}$ concentrations. The explanation is related to the size of the barium cation which does not intercalate completely in the crown ether cavity. This assumption is confirmed by the slight downfield shift of the signals in the ${ }^{1} \mathrm{H}$ NMR spectrum of dye $4 \mathbf{b}$ in the presence of $\mathrm{Ba}^{2+}$ cations compared to that in neat $\mathrm{CD}_{3} \mathrm{CN}$ (Supporting Information File 1, Figure S9 and Figure $\mathrm{S} 10)$.

A common behavior demonstrated in Figure 2 was observed: the fluorescence quantum yield of all dyes (Table 1) decreases if the concentration of the $\mathrm{Ba}^{2+}$ ions increases, i.e., the formation of the trans-dye- $\mathrm{Ba}^{2+}$ complexes causes the observed fluorescence decrease.

The optical parameters of all 4 dyes, including absorption maxima $\left(\lambda_{\max , a b s}\right)$, fluorescence emission maxima $\left(\lambda_{\max , f}\right)$, hypsochromic shift of the absorption maxima $\left(\Delta \lambda_{\max }\right)$, and fluo-

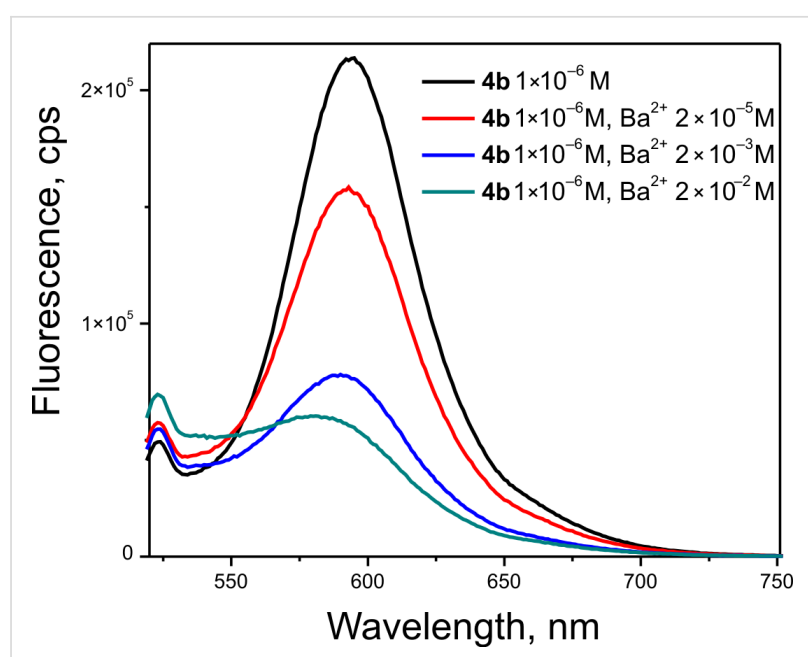

Figure 2: Dependence of the fluorescence of $4 b$ on the concentration of the $\mathrm{Ba}^{2+}$ ions. Excitation wavelength $\lambda_{\text {exc }}=488 \mathrm{~nm}$.

rescence quantum yields $\left(\Phi_{\mathrm{f}}\right)$ for different excitation wavelengths, obtained for the dyes in ACN solution at different $\mathrm{Ba}^{2+}$ concentrations are summarized in Table 1. The emission maximum of all dyes is at about $\lambda_{\text {max, }}=595 \mathrm{~nm}$ and does not change significantly upon $\mathrm{Ba}^{2+}$ ion complexation. No changes in the shape of the fluorescence curves were observed, when the excitation wavelength was tuned within the region of $\lambda_{\text {exc }}=400-550 \mathrm{~nm}$.

Generally one of the advantages of the presented $\mathrm{Ba}^{2+}$-crown ether containing styryl dye complexes as a MOST material is the extremely low intrinsic fluorescence which can be a precondition for higher quantum yields of the cis-trans photoisomerization reactions.

\begin{tabular}{|c|c|c|c|c|c|c|}
\hline Dye & $c_{\mathrm{M}} / c_{\mathrm{L}}$ & $\lambda_{\max , \mathrm{abs}}, \mathrm{nm}$ & $\Delta \lambda_{\text {abs }}$ & $\lambda_{\text {max }, \mathrm{f}}, \mathrm{nm}$ & $\begin{array}{l}\Phi_{\mathrm{f}} \% \\
\lambda_{\mathrm{exc}}=488 \mathrm{~nm}\end{array}$ & $\begin{array}{l}\Phi_{\mathrm{f}} \% \\
\lambda_{\mathrm{exc}}=440 \mathrm{~nm}\end{array}$ \\
\hline \multirow[t]{3}{*}{$4 a$} & 0 & 520 & & 597.6 & 5.9 & 1.9 \\
\hline & 1000 & 439 & 81 & 595 & 0.29 & 0.29 \\
\hline & 10000 & 439 & 81 & 595 & 0.34 & 0.37 \\
\hline \multirow[t]{3}{*}{$4 b$} & 0 & 523 & & 594 & 6.42 & 0.83 \\
\hline & 2000 & 438 & 85 & 588 & 1.9 & 0.38 \\
\hline & 10000 & 438 & 85 & 580.6 & 0.91 & 0.44 \\
\hline \multirow[t]{3}{*}{$4 c$} & 0 & 522 & & 593.8 & 0.23 & 0.4 \\
\hline & 1000 & 442 & 80 & 596 & 0.18 & 0.25 \\
\hline & 10000 & 442 & 80 & 596 & 0.14 & 0.13 \\
\hline \multirow[t]{3}{*}{$4 d$} & 0 & 521 & & 599 & 0.56 & 0.77 \\
\hline & 1000 & 441 & 80 & 596 & 0.31 & 0.32 \\
\hline & 10000 & 441 & 80 & 594 & 0.49 & 0.58 \\
\hline
\end{tabular}




\section{Real-time E/Z-photoisomerization of dyes $4 \mathbf{a}-\mathbf{d}$ and their complexes}

The photoisomerization of free dyes $\mathbf{4 a -}-\mathbf{d}$ and dye $-\mathrm{Ba}^{2+}$ inclusion complexes were investigated in real time mode upon irradiation with visible light $(\lambda=488 \mathrm{~nm})$ close to their absorption maxima. Figure 3 a illustrates the characteristic changes in the absorption spectra of dye $\mathbf{4 b}-\mathrm{Ba}^{2+}$ complex under optical excitation with $\lambda=488 \mathrm{~nm}$ and intensity of $14 \mathrm{~mW} \mathrm{~cm}^{-2}$. The temporal evolution of the absorption at specific wavelength of $\lambda_{\mathrm{abs}}=500 \mathrm{~nm}$ is demonstrated in Figure $3 \mathrm{~b}$ : during the first time interval from $t_{1}=10 \mathrm{~s}$ up to $t_{2}=180 \mathrm{~s}$ the absorption is decreasing monotonically, as a result of $\pi \rightarrow \pi$ transition in the trans isomer of the free dye and its $\mathrm{Ba}^{2+}$ complex. During the next time interval for $t_{3}>180 \mathrm{~s}$, the optical excitation was terminated and constant increase of the optical absorption was observed.

The degree $(R)$ of trans-to-cis photoisomerization at the photostationary state was evaluated from Equation 3:

$$
R=\left(A_{0}-A_{\infty}\right) / A_{0}
$$

where $A_{0}$ is the absorption before irradiation and $A_{\infty}$ is the absorption at the photostationary state. It was found that the rate of the photoisomerization process and the degree of conversion trans-to-cis isomer depends strongly on the $\mathrm{Ba}^{2+}$ concentration. The $c$ is isomers formed upon irradiation are thermally unstable and revert to the trans isomers in the dark [23]. The rates of trans-to-cis isomerization were determined for several $\mathrm{Ba}^{2+}$ concentrations in the range of $2 \times 10^{-3} \mathrm{M}$ up to $1 \mathrm{M}$ at a fixed dye concentration $\left(1 \times 10^{-4} \mathrm{M}\right)$ for all dyes. The kinetic data were found to fit well to a single exponential function (Equa- tion 1), giving a rate constant $(k)$ corresponding to a lifetime $(1 / k)[18]$ :

$$
A=A_{\infty}+\left(A_{0}-A_{\infty}\right) \exp (-k t)
$$

where $A_{0}$ and $A_{\infty}$, are the initial and final absorptions, $A$ is the absorption at $500 \mathrm{~nm}$ at a time $t$ after termination of the irradiation. In all cases, after irradiation ceased, complete reversion toward the initial absorption spectrum was observed. As a rule, the reversion from the cis to the trans isomer leads to a gradual increase in the intensity of the absorption maximum. The photoisomerization data for all 4 dyes are summarized in Table 2.

Generally, the addition of $\mathrm{Ba}^{2+}$ ions was found to increase substantially the lifetime of the cis isomers. Under the abovementioned conditions the $c i s-\mathbf{4 b}-\mathrm{Ba}^{2+}$ complex was detected to be most stable, while dye $\mathbf{4 d}$ formed stable cis-4d- $\mathrm{Ba}^{2+}$ complex only at a higher concentration of $\mathrm{Ba}^{2+}$ ions $(1 \mathrm{M})$.

Figure 4 is an additional demonstration of the ability of dye $\mathbf{4 b}$ to undergo trans-to-cis photoisomerization in its free form and in complex with $\mathrm{Ba}^{2+}$. The absorption band corresponding to the $\pi \rightarrow \pi$ transition in the cis isomer (at around $280 \mathrm{~nm}$ and $320 \mathrm{~nm}$, shown in Figure 4), as for the free dye $\mathbf{4 b}$, increased with the irradiation time, suggesting that isomerization from trans to a cis form of the free dye or its $\mathrm{Ba}^{2+}$ complex proceeded until a photostationary state was reached. As can be seen from Figure 4 the trans-to-cis isomerization takes place to a higher extent in the free form of the dye than in the complex. However, the lifetimes of the free $c i s$ form is extremely short in comparison to that of the complex. The degree of photoisomerization of the new dye $\mathbf{4 b}$ is apparently higher than that of the
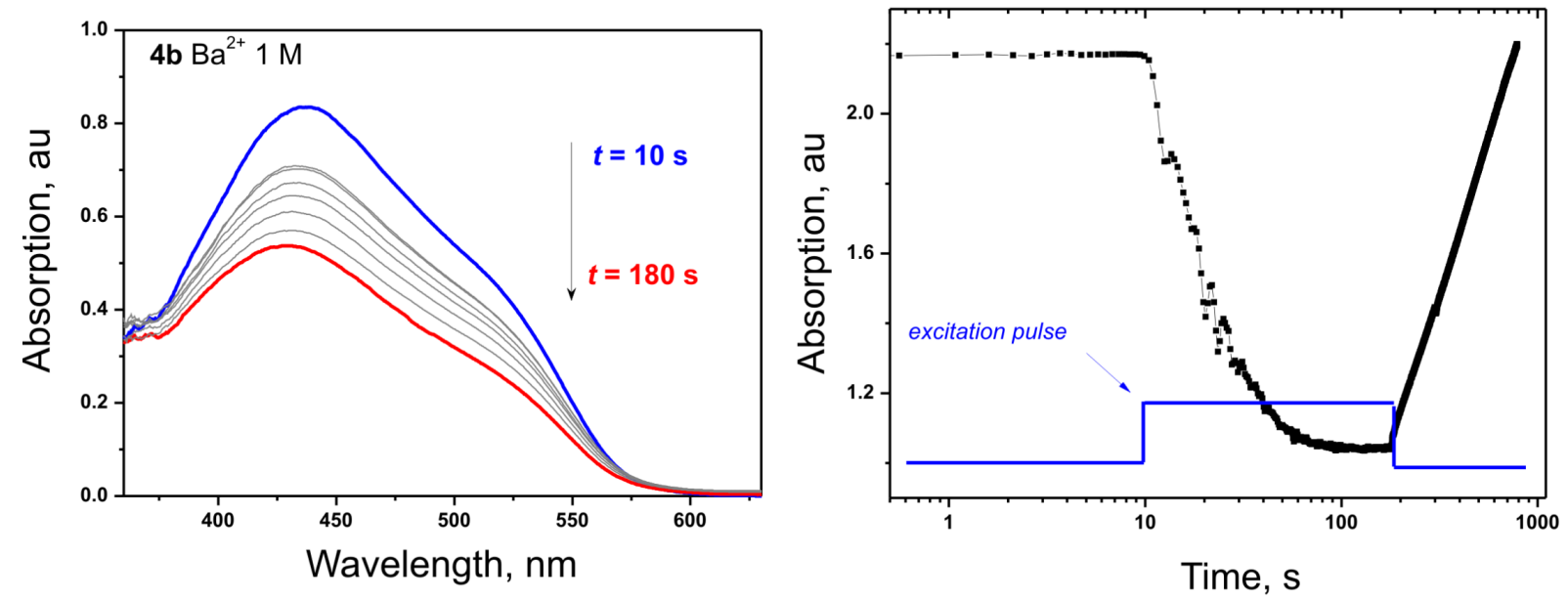

Figure 3: a) Dependence of absorption spectra of dye $4 \mathrm{~b}\left(c_{\mathrm{L}}=1.0 \times 10^{-4} \mathrm{M}\right)$ with $\mathrm{Ba}^{2+}\left(c_{\mathrm{M}}=1 \mathrm{M}\right)$ on the irradiation time. $\left.b\right)$ Temporal absorption evolution, measured at $\lambda_{\mathrm{abs}}=500 \mathrm{~nm}$, upon irradiation. Experimental conditions: Excitation wavelength $\lambda_{\mathrm{exc}}=488 \mathrm{~nm}$; excitation intensity $14 \mathrm{~mW} \mathrm{~cm}^{-2}$, solvent, ACN; pulse duration $t=180 \mathrm{~s}$. 
Table 2: Degree $(R)$ of trans-to-cis photoisomerization at the photostationary state, rate constants $(k)$ and lifetime of trans-to-cis isomerization.

\begin{tabular}{lllll}
$\begin{array}{l}\text { Dye } \\
M\end{array}$ & $\begin{array}{ll}\mathrm{Ba}\left(\mathrm{ClO}_{4}\right)_{2} \\
\mathrm{M}\end{array}$ & $R$ & $\begin{array}{l}\text { Lifetime } \\
\mathrm{s}\end{array}$ & $\begin{array}{l}k \\
\mathrm{~s}^{-1}\end{array}$ \\
\hline $\mathbf{4 a}$ & 0 & 0.19 & 31 & $32.6 \times 10^{-3}$ \\
$1.0 \times 10^{-4}$ & $2.0 \times 10^{-3}$ & 0.53 & 69 & $14.4 \times 10^{-3}$ \\
& $2.0 \times 10^{-2}$ & 0.52 & 264 & $3.8 \times 10^{-3}$ \\
& $2.0 \times 10^{-1}$ & 0.56 & 284 & $3.5 \times 10^{-3}$ \\
& 1 & 0.53 & 342 & $2.9 \times 10^{-3}$ \\
$\mathbf{4 b}$ & 0 & 0.35 & 148 & $6.0 \times 10^{-3}$ \\
$1.0 \times 10^{-4}$ & $2.0 \times 10^{-3}$ & 0.82 & 292 & $3.4 \times 10^{-3}$ \\
& $2.0 \times 10^{-2}$ & 0.74 & 279 & $3.6 \times 10^{-3}$ \\
& $2.0 \times 10^{-1}$ & 0.54 & 481 & $2.1 \times 10^{-3}$ \\
& 1 & 0.39 & 514 & $1.9 \times 10^{-3}$ \\
$\mathbf{4 c}$ & 0 & 0.00 & 0 & 0 \\
$1.0 \times 10^{-4}$ & $2.0 \times 10^{-3}$ & 0.00 & 0 & 0 \\
& $2.0 \times 10^{-2}$ & 0.08 & 0 & 0 \\
& $2.0 \times 10^{-1}$ & 0.52 & 330 & $3.0 \times 10^{-3}$ \\
$\mathbf{4 d}$ & 1 & 0.44 & 390 & $2.6 \times 10^{-3}$ \\
$1.0 \times 10^{-4}$ & 0 & 0.21 & 18 & $55.0 \times 10^{-3}$ \\
& $2.0 \times 10^{-3}$ & 0.23 & 20.9 & $47 \times 10^{-3}$ \\
& $2.0 \times 10^{-2}$ & 0.22 & 30.7 & $32 \times 10^{-3}$
\end{tabular}

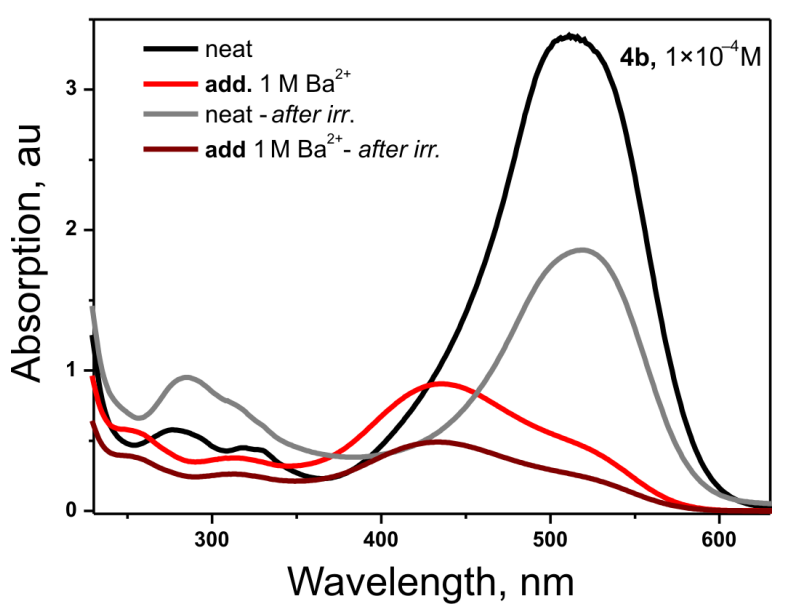

Figure 4: UV-vis absorption spectra of dye $4 b\left(1.0 \times 10^{-4} \mathrm{M}\right)$ free and in complex with $\mathrm{Ba}^{2+}(1 \mathrm{M})$ before and after the end of the exposure at $\lambda=488 \mathrm{~nm}$.

known structure (4a). From one side it can be supposed that dye 4a aggregated much faster than its methyl-substituted analogue 4b. From another hand the substituent in the 5-position of the benzothiazole heterocycle sterically hinders the rotation of the alkylsulfo-anchoring group and thus plays the role of a controller with regard to its direction towards the crown ether. This finding is a resemblance to the results from reference [24] where the 5-methoxy-substituted benzothiazole styryl-crown ethers demonstrated higher quantum yields of trans-to-cis photoisomerization.

\section{Insight from electronic structure calculations}

To rationalize the experimental findings, we performed density functional theory (DFT) calculations at the B3LYP/6-31+G(d,p) level. The first step in the molecular modelling investigation was the optimization of the molecular structures of the $c i s$ and trans isomers of dyes $\mathbf{4 a}-\mathbf{d}$ (with the $-\left(\mathrm{CH}_{2}\right)_{n} \mathrm{SO}_{3}{ }^{-}(n=3,4)$ tails oriented to be in proximity to the aza-15-crown-5 fragments) in the gas phase (Figure 5). The thermochemical data for these are calculated at $298.15 \mathrm{~K}$ and a pressure of $1 \mathrm{~atm}$. In Table 3 we report the enthalpies $(H)$ for the cis and trans isomers and the energy storage capacity $(\Delta H)$ calculated as the difference in enthalpy between the cis and trans isomers. B3LYP calculations in the gas phase predict the trans forms of the dyes $\mathbf{4 a - d}$ to be more stable. The cis forms are higher in energy by only 3.3 and $3.0 \mathrm{~kJ} \mathrm{~mol}^{-1}$ for $\mathbf{4 a}$ and $\mathbf{4 b}$, respectively. The enthalpy differences calculated for dyes $\mathbf{4 c}$ and $\mathbf{4 d}$ are much higher $\left(69.3 \mathrm{~kJ} \mathrm{~mol}^{-1}(\mathbf{4 c})\right.$ and $67.9 \mathrm{~kJ} \mathrm{~mol}^{-1}(\mathbf{4 d})$, respectively).

Compounds 4a-d can bind metal species at both isomeric forms. To determine the geometries of the 1:1 complexes with $\mathrm{Ba}^{2+}$ cations the metal cations were placed in the crown ether's 


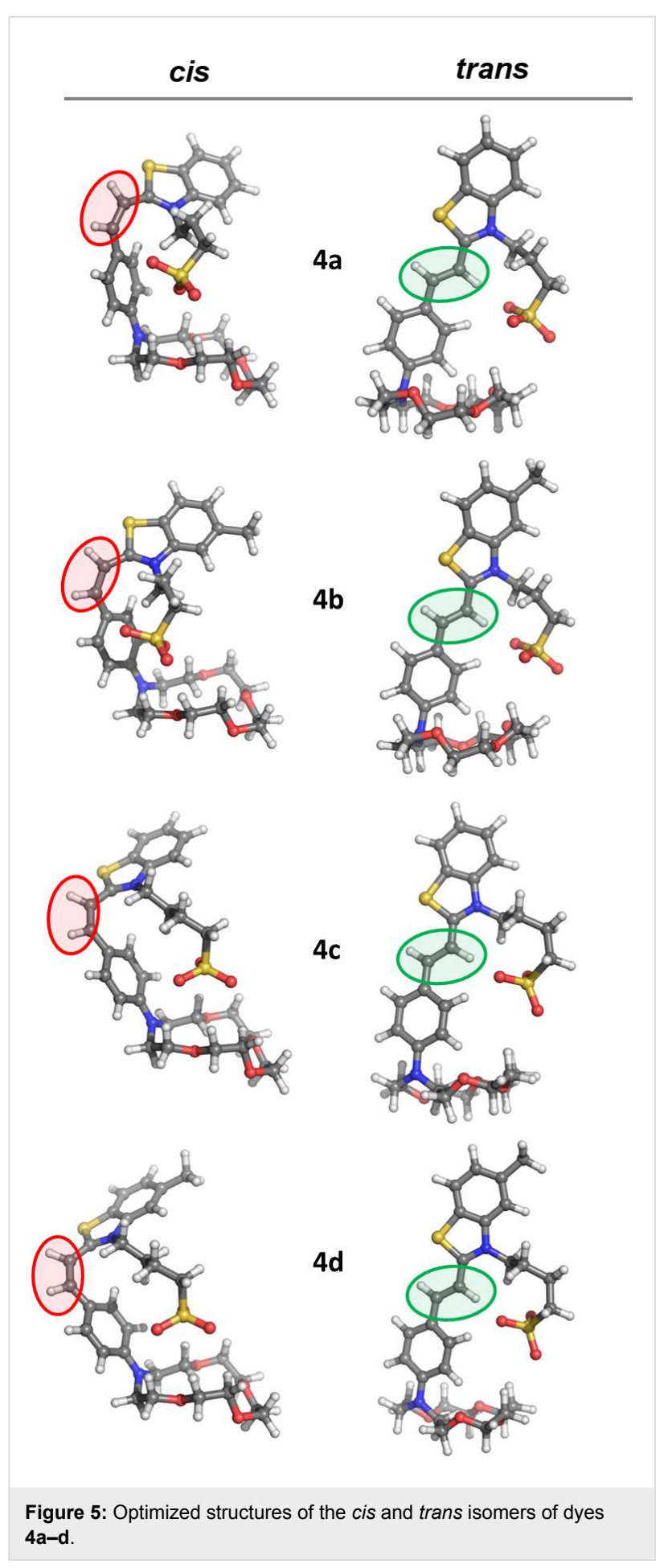

cavity and allowed to relax. In the optimized dye- $\mathrm{Ba}^{2+}$ complexes the metal cations are displaced "above" the crown ether's cavity. Figure 6 depicts the gas-phase geometries of the $\mathrm{Ba}^{2+}$ complexes of the cis and trans isomer of $\mathbf{4 b}$.

The calculated enthalpies for the complex-formation reaction dye $+\mathrm{Ba}^{2+} \rightarrow[\text { dye-Ba }]^{2+}$ in the gas phase, where dye $=\mathbf{4 a}-\mathbf{d}$,
Table 3: Calculated enthalpies $(H)$ for the cis and trans isomers and storage energies $(\Delta H)$ for the systems studied in the gas phase and in acetonitrile solution.

\begin{tabular}{lll} 
Compound & \multicolumn{2}{c}{$\Delta H, \mathrm{~kJ} \mathrm{~mol}^{-1}$} \\
\cline { 2 - 3 } & gas phase & acetonitrile \\
\hline 4a & 3.3 & 39.7 \\
4b & 3.0 & 42.9 \\
4c & 69.3 & 32.3 \\
4d & 67.9 & 31.8
\end{tabular}

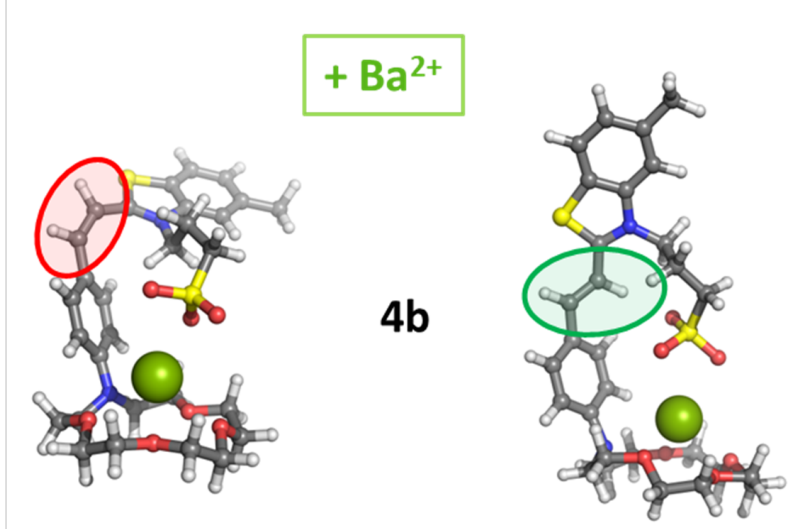

Figure 6: Optimized structures of the $\mathrm{Ba}^{2+}$-complexes of cis and trans isomer of $\mathbf{4 b}$.

with bare metal cations are listed in Table 4 . The results obtained demonstrate that all reactions in the gas phase are predicted to be favorable. The $\Delta \Delta H^{1}$ values calculated for $\mathrm{Ba}^{2+}$ complex formation with the trans isomers of $\mathbf{4 a - d}$ are more negative than the values obtained for the respective $c i s$ isomers.

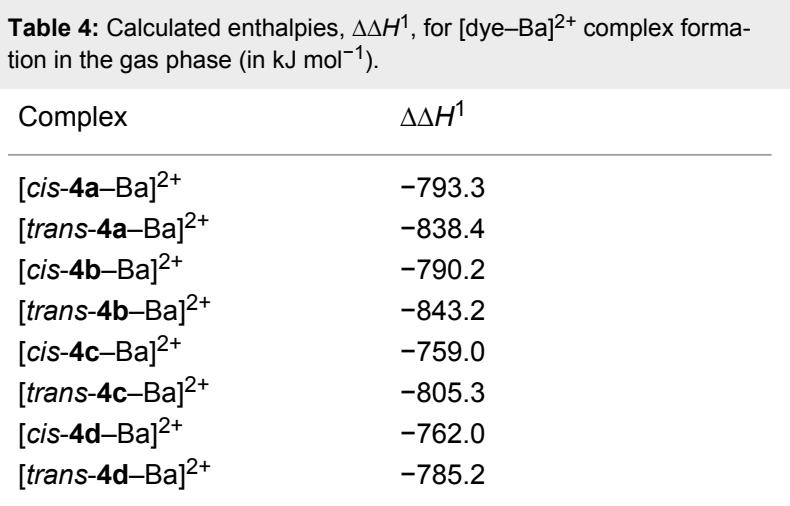

The complex formation processes between dyes with shorter $-\left(\mathrm{CH}_{2}\right)_{n} \mathrm{SO}_{3}{ }^{-}$tail $(n=3)$ are characterized by more negative $\Delta \Delta H^{1}$ values than those calculated for the dyes equipped with longer tails $(n=4)$, a trend corresponding to the trends in the 
experimentally derived stability constants. Conventional solvent treatment by methods like the polarizable continuum model (PCM) did not provide a good quantitative agreement with the experimental stability constants [23] so the data for $\Delta \Delta H$ in acetonitrile are not provided.

Time-dependent density functional theory (TDDFT) calculations were used to probe the electronic reorganizations upon excitation. TDPBE0 calculations with the $6-31+\mathrm{G}(\mathrm{d}, \mathrm{p})$ basis set for all atoms (except for $\mathrm{Ba}$ ) and with the Stuttgart-Dresden SDD effective core potential (ECP) basis set for Ba predict one intensive band for all compounds in the range of 400-500 nm. The calculated optical parameters such as the absorption maximum $\left(\lambda_{\max }\right)$, oscillator strength $(f)$ and frontier orbital energy levels for the trans isomers of $\mathbf{4 a - d}$ are listed in Table 5 . The positions and intensities of the bands are consistent with the experimentally observed ones. The first excited states are determined by HOMO (highest occupied molecular orbital) $\rightarrow$ LUMO (lowest unoccupied molecular orbital) transitions.

The simulated spectra with spectral lifetime broadening (Gaussian function) with a full width at half-maximum (FWHM) of $0.15 \mathrm{eV}$ and a height proportional to the oscillator strength for each transition spectrum for dye $\mathbf{4 b}$ and its
$\mathrm{Ba}^{2+}$ complex (Figure 7) are consistent with the experimental ones. The experimentally measured substantial hypo- and hypsochromic shift in the absorption spectra upon $\mathrm{Ba}^{2+}$ addition are also observed in the simulated spectra of the theoretically modeled structures of the dyes and the respective complexes.

The simulated spectra of the metal-free and $\mathrm{Ba}^{2+}$ complexed cis form of compound $\mathbf{4 b}$ are also presented in Figure 7. The oscillator strengths of the $c i$ f forms, calculated at the same computational level, are found to be significantly lower than those calculated for the respective trans forms (metal-free compound trans $\mathbf{- 4 b}$ and trans $\mathbf{- 4 b}-\mathrm{Ba}$ complex). These results correspond to the experimentally observed gradual increase in the intensity of the absorption maximum upon cis-to-trans reversion.

\section{Conclusion}

Four benzothiazolium crown ether-containing styryl dyes (two known and two novel compounds) were synthesized through an optimized synthetic procedure. The photophysical properties of the new dyes were investigated in the absence and presence of $\mathrm{Ba}^{2+}$ cations and compared with those of the known dyes. The optimal conditions for the trans-to-cis photoisomerization of the styryl-crown ether containing dyes were identified. The dyes $\mathbf{4 b}$

Table 5: TDDFT/PBEO calculated absorption maxima ( $\lambda_{\max }$ ), oscillator strength $(f)$ HOMO and LUMO energies and energy difference (HOMO-LUMO gap, HLG) for the trans isomers of compounds $\mathbf{4 a - d}$ in acetonitrile.

\begin{tabular}{llllrr} 
Compound & $\lambda_{\max }, \mathrm{nm}$ & $f$ & HOMO, eV & \multicolumn{2}{c}{ LUMO, eV } \\
\hline 4a & 477 & 1.58 & -5.71 & -2.98 & 2.73 \\
4b & 481 & 1.63 & -5.64 & -2.93 & 2.71 \\
4c & 482 & 1.63 & -5.58 & -2.90 & 2.69 \\
4d & 483 & 1.65 & -5.56 & -2.87 & 2.69
\end{tabular}
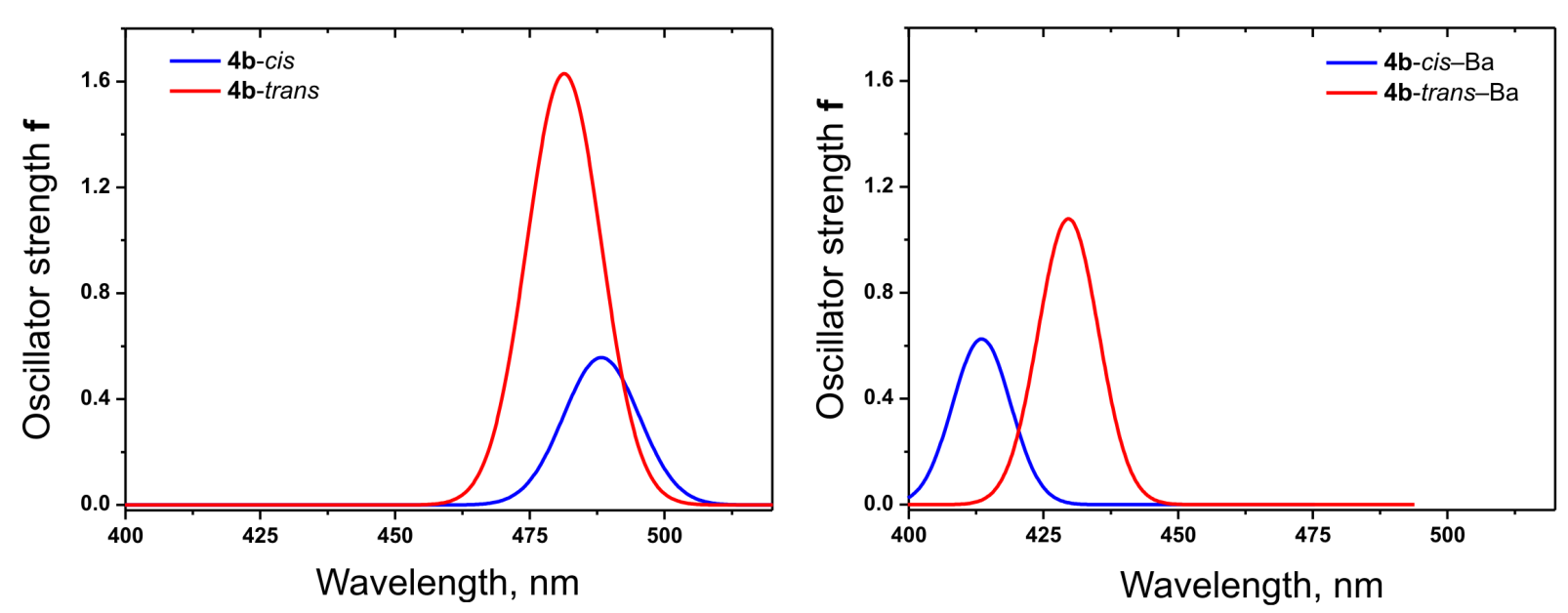

Figure 7: Simulated spectra with spectral lifetime broadening TDPBE0 spectra in ACN for dye $\mathbf{4 b}$ and its $\mathrm{Ba}^{2+}$ complex. 
and 4d with substituents in 5-position of the benzothiazole moiety demonstrated much better photophysical properties as molecular switches and MOST materials in comparison with the unsubstituted known analogs. The calculated thermodynamic changes associated with metal-ion complexation in the gas phase match the trends in the experimental stability constants.

\section{Experimental General}

All solvents used in the present work were commercially available (HPLC grade). The starting materials $\mathbf{1 a}, \mathbf{1 b}, \mathbf{2 a}$, and $\mathbf{2 b}$ were commercially available and were used as supplied. Melting points were determined on a Kofler apparatus and are uncorrected. NMR spectra were obtained on a Bruker Avance III 500 DRX $600 \mathrm{MHz}$ spectrometer in DMSO- $d_{6}$. The MALDI-TOF/TOF spectra were measured at Bruker "RapifeX" at MPIP, Germany. The stepwise experimental procedures for the synthesis of compounds $\mathbf{2}-\mathbf{4}$ and characterization data are given in Supporting Information File 1. 4-(Aza-15-crown5)benzocarbaldehyde (3) was synthesized using a slightly modified procedure [16,17].

UV-vis spectra were measured on a Unicam 530 UV-vis spectrophotometer in conventional quartz cells of $1 \mathrm{~cm}$ path length. The spectral bandwidth and the scan rate were $1 \mathrm{~nm}$ and $140 \mathrm{~nm} \mathrm{~min}{ }^{-1}$, respectively. Stock solutions of each compound were prepared in spectroscopic grade acetonitrile (ACN) and all experiments were carried out in red light and at room temperature. Complex formation of dyes with $\mathrm{Ba}\left(\mathrm{ClO}_{4}\right)_{2}$ was studied by spectrophotometric titration. In the experiment aliquots of a solution containing known concentrations of dyes and of $\mathrm{Ba}\left(\mathrm{ClO}_{4}\right)_{2}$ were added to a solution of dyes alone at the same concentration. So the absorption spectra were recorded for solutions with identical total dye concentration $\left(1 \times 10^{-5} \mathrm{M}\right)$ and variable total $\mathrm{Ba}\left(\mathrm{ClO}_{4}\right)_{2}$ concentration ranging from $1 \times 10^{-5} \mathrm{M}$ to $5 \times 10^{-1} \mathrm{M}$ in $\mathrm{ACN}$.

Emission spectra were recorded on FluoroLog3-22, Horiba Jobin Yvon spectrofluorometer with Quanta- $\varphi$ accessory having a large $150 \mathrm{~mm}$ integrating sphere for the quantum yield measurements. All spectra we recorded using quartz cells of $1 \mathrm{~cm}$ path length. The solution concentrations were chosen to give an absorbance $\leq 0.05$ at the excitation wavelength of 440 and $488 \mathrm{~nm}$.

The photoisomerization of the dyes and their complexes was performed by irradiating the samples in quartz cells $(1 \mathrm{~cm})$ with $16 \mathrm{~mW}$ laser (Qioptiq iFLEX2000-P-2-488) at $\lambda=488 \mathrm{~nm}$ for $3 \mathrm{~min}$, a time which was found to be long enough to reach a photostationary state. The kinetics of the cis-trans thermal isomerization were studied by measuring the absorbance at a fixed wavelength in the dark as a function of time after irradiation stopped until the initial absorbance value before excitation was reached. The absorbance was measured by Ocean Optic HR2000+ high resolution USB fiber optic spectrometer fitted with $500 \mathrm{~nm}$ interference filter in the incident beam $(10 \mathrm{~nm}$ bandwidth). During the irradiation and kinetic studies, the solutions were intensively magnetically stirred. A cuvette holder for fluorescent measurements was used allowing recording of the absorbance spectra during the laser irradiation in the perpendicular direction and immediately after the stop of irradiation.

\section{Computational details}

Equilibrium geometries and intermolecular interaction energies for the host-guest assemblies between the dyes and metal cations were obtained by density functional theory (DFT) calculations using the B3LYP functional $[25,26]$ (the most often used functional for organic molecules and complexes) and the 6-31+G(d,p) [27-29] basis set for the lighter atoms (C, O, S, N, $\mathrm{H})$ and SDD pseudopotential for Ba atoms as implemented in the Gaussian 09 program package [30]. Frequency calculations for each optimized structure were performed at the same level of theory. No imaginary frequency was found for the lowest energy configurations of any of the optimized structures. In order to take into account the solvent effect induced by the acetonitrile solvent environment, the equilibrium geometries of the host-guest constituents and complexes were reoptimized considering the PCM (polarizable continuum model) solvent model [31]. The so-called basis set superposition error (BSSE) was not taken into account for the geometry optimization and intermolecular energy calculation. Time-dependent density functional theory calculations (TDDFT) using Perdew-Burke-Ernzerhof exchange-correlation functional (PBE0) were performed to compute the 10 lowest excited states of each structure $[6-31+\mathrm{G}(\mathrm{d}, \mathrm{p})$ basis set for all atoms except $\mathrm{Ba}$. PyMOL molecular graphics system was used for generation of the molecular graphics images [32].

\section{Supporting Information}

\section{Supporting Information File 1}

Experimental procedures for the synthesis of compounds 2-4 and characterization data of the new compounds. [https://www.beilstein-journals.org/bjoc/content/ supplementary/1860-5397-15-106-S1.pdf]

\section{Acknowledgements}

The financial support from Bulgarian National Science Fund under the project "SunStore" (DFNI E 02/11 2014) and Materials Networking (Twinning-692146) is gratefully acknowledged. 


\section{ORCID ${ }^{\circledR}$ iDs}

Snejana M. Kitova - https://orcid.org/0000-0001-6086-655X Stanimir S. Stoyanov - https://orcid.org/0000-0002-7830-1538 Stanislav B. Baluschev - https://orcid.org/0000-0002-0742-0687 Silvia E. Angelova - https://orcid.org/0000-0003-4717-8028 Aleksey A. Vasilev - https://orcid.org/0000-0003-2199-5644

\section{References}

1. Gust, D.; Andréasson, J.; Pischel, U.; Moore, T. A.; Moore, A. L. Chem. Commun. 2012, 48, 1947-1957. doi:10.1039/c1cc15329c

2. Pischel, U.; Andréasson, J.; Gust, D.; Pais, V. F. ChemPhysChem 2013, 14, 28-46. doi:10.1002/cphc.201200157

3. Raimondo, C.; Crivillers, N.; Reinders, F.; Sander, F.; Mayor, M.; Samorì, P. Proc. Natl. Acad. Sci. U. S. A. 2012, 109, 12375-12380. doi:10.1073/pnas.1203848109

4. Orgiu, E.; Crivillers, N.; Herder, M.; Grubert, L.; Pätzel, M.; Frisch, J.; Pavlica, E.; Duong, D. T.; Bratina, G.; Salleo, A.; Koch, N.; Hecht, S.; Samorì, P. Nat. Chem. 2012, 4, 675-679. doi:10.1038/nchem.1384

5. Crivillers, N.; Orgiu, E.; Reinders, F.; Mayor, M.; Samorì, P. Adv. Mater. (Weinheim, Ger.) 2011, 23, 1447-1452. doi:10.1002/adma.201003736

6. Kucharski, T. J.; Tian, Y.; Akbulatov, S.; Boulatov, R. Energy Environ. Sci. 2011, 4, 4449-4472. doi:10.1039/c1ee01861b

7. Lennartson, A.; Roffey, A.; Moth-Poulsen, K. Tetrahedron Lett. 2015, 56, 1457-1465. doi:10.1016/j.tetlet.2015.01.187

8. Börjesson, K.; Lennartson, A.; Moth-Poulsen, K. ACS Sustainable Chem. Eng. 2013, 1, 585-590. doi:10.1021/sc300107z

9. Börjesson, K.; Dzebo, D.; Albinsson, B.; Moth-Poulsen, K J. Mater. Chem. A 2013, 1, 8521-8524. doi:10.1039/c3ta12002c

10. Baluschev, S.; Miteva, T.; Yakutkin, V.; Nelles, G.; Yasuda, A.; Wegner, G. Phys. Rev. Lett. 2006, 97, 143903. doi:10.1103/physrevlett.97.143903

11. Baluschev, S.; Katta, K.; Avlasevich, Y.; Landfester, K. Mater. Horiz. 2016, 3, 478-486. doi:10.1039/c6mh00289g

12. Dreos, A.; Wang, Z.; Udmark, J.; Ström, A.; Erhart, P.; Börjesson, K.; Nielsen, M. B.; Moth-Poulsen, K. Adv. Energy Mater. 2018, 8 , 1703401. doi:10.1002/aenm.201703401

13. Wang, Z.; Udmark, J.; Börjesson, K.; Rodrigues, R.; Roffey, A.; Abrahamsson, M.; Nielsen, M. B.; Moth-Poulsen, K. ChemSusChem 2017, 10, 3049-3055. doi:10.1002/cssc.201700679

14. Alfimov, M. V.; Gromov, S. P.; Lednev, I. K. Chem. Phys. Lett. 1991, 185, 455-460. doi:10.1016/0009-2614(91)80242-p

15. Gromov, S. P.; Fedorova, O. A.; Ushakov, E. N.; Stanislavskii, O. B.; Lednev, I. K.; Alfimov, M. V. Dokl. Akad. Nauk. SSSR 1991, 317, 1134-1139.

16. Lednev, I. K.; Fyedorova, O. A.; Gromov, S. P.; Alfimov, M. V.; Moore, J. N.; Hester, R. E. Spectrochim. Acta, Part A 1993, 49 1055-1063. doi:10.1016/0584-8539(93)80065-i

17. Lednev, I. K.; Hester, R. E.; Moore, J. N. J. Chem. Soc., Faraday Trans. 1997, 93, 1551-1558. doi:10.1039/a607389a

18. Lednev, I. K.; Ye, T.-Q.; Hester, R. E.; Moore, J. N. J. Phys. Chem. A 1997, 101, 4966-4972. doi:10.1021/jp970685y

19. Lednev, I. K.; Hester, R. E.; Moore, J. N. J. Am. Chem. Soc. 1997, 119, 3456-3461. doi:10.1021/ja964154j

20. Gromov, S. P.; Alfimov, M. V. Russ. Chem. Bull. 1997, 46, 611-636. doi:10.1007/bf02495186
21. Gromov, S. P. Russ. Chem. Bull. 2008, 57, 1325-1350. doi:10.1007/s11172-008-0174-9

22. Li, Q.; Lin, G.-L.; Peng, B.-X.; Li, Z.-X. Dyes Pigm. 1998, 38, 211-218. doi:10.1016/s0143-7208(97)00088-0

23. Gutten, O.; Rulišek, L. Inorg. Chem. 2013, 52, 10347-10355. doi:10.1021/ic401037x

24. Tulyakova, E. V.; Vermeersch, G.; Gulakova, E. N.; Fedorova, O. A.; Fedorov, Y. V.; Micheau, J. C.; Delbaere, S. Chem. - Eur. J. 2010, 16, 5661-5671. doi:10.1002/chem.200903226

25. Becke, A. D. J. Chem. Phys. 1993, 98, 5648-5652. doi:10.1063/1.464913

26. Lee, C.; Yang, W.; Parr, R. G. Phys. Rev. B 1988, 37, 785-789. doi:10.1103/physrevb.37.785

27. Ditchfield, R.; Hehre, W. J.; Pople, J. A. J. Chem. Phys. 1971, 54, 724-728. doi:10.1063/1.1674902

28. Hehre, W. J.; Ditchfield, R.; Pople, J. A. J. Chem. Phys. 1972, 56, 2257-2261. doi:10.1063/1.1677527

29. Clark, T.; Chandrasekhar, J.; Spitznagel, G. W.; Schleyer, P. V. R. J. Comput. Chem. 1983, 4, 294-301. doi:10.1002/jcc.540040303

30. Gaussian 09; Gaussian Inc.: Wallingford, CT, 2013.

31. Miertuš, S.; Scrocco, E.; Tomasi, J. Chem. Phys. 1981, 55, 117-129. doi:10.1016/0301-0104(81)85090-2

32. The PyMOL Molecular Graphics System, Version 1.7.6.6; Schrödinger, LLC.

\section{License and Terms}

This is an Open Access article under the terms of the Creative Commons Attribution License (http://creativecommons.org/licenses/by/4.0). Please note that the reuse, redistribution and reproduction in particular requires that the authors and source are credited.

The license is subject to the Beilstein Journal of Organic Chemistry terms and conditions: (https://www.beilstein-journals.org/bjoc)

The definitive version of this article is the electronic one which can be found at: doi:10.3762/bjoc. 15.106 